\title{
Ground-Penetrating Radar Investigations along Hajipur Fault: Himalayan Frontal Thrust_-Attempt to Identify Near Subsurface Displacement, NW Himalaya, India
}

\author{
Javed N. Malik, Ashutosh Kumar, Sravanthi Satuluri, \\ Bishuddhakshya Puhan, and Asmita Mohanty \\ Department of Civil Engineering, Indian Institute of Technology Kanpur, Kanpur 208016, India \\ Correspondence should be addressed to Javed N. Malik, javed@iitk.ac.in
}

Received 3 November 2011; Accepted 25 January 2012

Academic Editor: Raffaele Solimene

Copyright ( 2012 Javed N. Malik et al. This is an open access article distributed under the Creative Commons Attribution License, which permits unrestricted use, distribution, and reproduction in any medium, provided the original work is properly cited.

\begin{abstract}
The study area falls in the mesoseismal zone of 1905 Kangra earthquake (Mw 7.8). To identify appropriate trenching site for paleoseismic investigation and to understand the faulting geometry, ground-penetrating radar (GPR) survey was conducted across a Hajipur Fault (HF2) scarp, a branching out fault of Himalayan Frontal Thrust (HFT) in a foot hill zone of NW Himalaya. Several 2D and 3D profiles were collected using $200 \mathrm{MHz}$ antenna with SIR 3000 unit. A 2D GPR profile collected across the HF2 scarp revealed prominent hyperbolas and discontinuous-warped reflections, suggesting a metal pipe and a zone of deformation along a low-angle thrust fault, respectively. The 3D profile revealed remarkable variation in dip of the fault plane and pattern of deformation along the strike of the fault.
\end{abstract}

\section{Introduction}

Paleoseismology defines the study of prehistoric earthquakes, especially their location, timing, and size [1-8]. The paleoseismic studies have attained a great pace in seismically active regions of the world $[7,9]$. The investigation is mainly emphasized towards identification of surface manifestation of deformation and near subsurface displacements on active fault related to past earthquakes. It has usually been experienced that the preservation of active tectonic landforms along the mountain fronts is difficult because of ongoing dynamic fluvial processes causing high degree of erosion and deposition $[10,11]$. Due to the removal of such feature, it becomes difficult to identify appropriate site for trenching to undertake paleoseismic studies. Several geophysical techniques to map the subsurface deformation, for example, seismic reflection and refraction, resistivity survey, ground-penetrating radar (GPR) have been used. The seismic reflection-refraction method has been used to get good resolution subsurface profile up to $\geq 100 \mathrm{~m}$, but submeter resolution is not possible. Since the Groundpenetrating Radar (GPR) technique gives a high-resolution profile of shallow subsurface succession up to submeter resolution, it has been extensively used for geological studies since the 1990s [12].

Since a decade, the GPR technique has been widely used for different studies for mapping near subsurface displacements in the young Quaternary sediments related to active faulting, for identifying neotectonic faulting activity and liquefaction features like sand-blows (e.g., [10-20]). It has also proved as an important tool in locating archeological sites (e.g., [21-24]). Along with this GPR has been quite useful towards identifying appropriate site to undertake trenching for detailed paleoseismic studies along active faults in an area, where surface manifestation of active faulting is sparsely preserved $[10,11,16]$.

The convergence and ongoing collision between Indian and Eurasian plates has kept the Himalayan arc to be one of the most seismically active regions of the world; therefore, seismic hazard assessment is one of the major concern. The built-up strain is released episodically along the active fault systems in Himalaya [20, 25]. This is well justified by the occurrence of large-magnitude earthquakes, namely, 


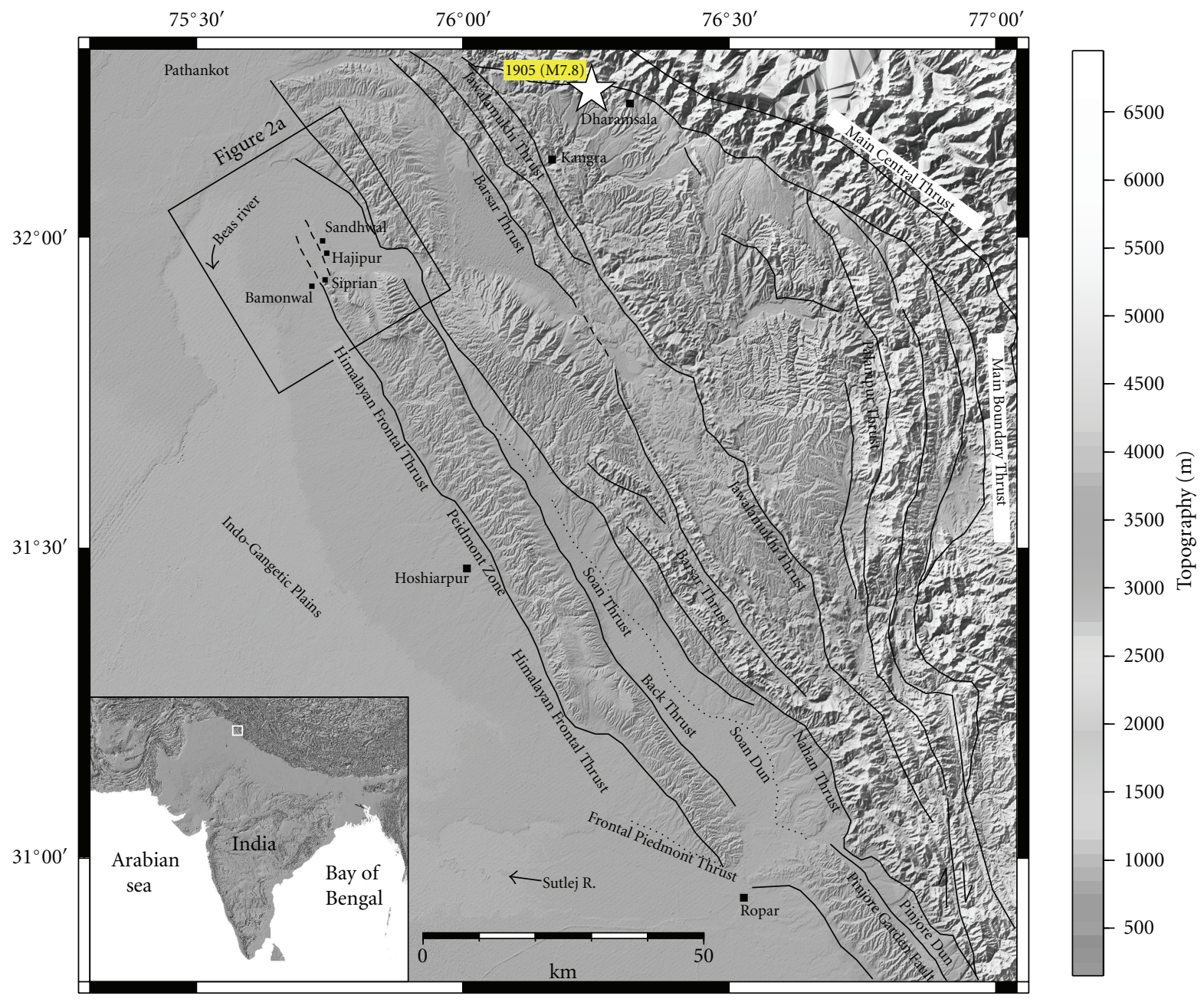

FIGURE 1: SRTM data of study area illustrating major faults marked by continuous lines and major geomorphic divisions around north west Himalaya. Box on top left marks the area of study which was shown in Figure 2. Inset shows DEM of India with location of study area.

1905 Kangra (Mw 7.8), 1934 Bihar (Mw 8.1), 1950 Upper Assam (Mw 8.4), and recent 2005 Muzaffarabad (Mw 7.6) earthquakes [8, 20, 26-28] (Figure 1). A very few studies have been taken up so far in Himalayan region attempting to map the surface manifestation of the past earthquake and to undertake paleoseismic investigation by excavating trenches across active fault scarps. Identification and mapping of such features, understanding the pattern of deformation along with known paleoseismic event are extremely important for proper seismic hazard assessment. In this paper, we discuss GPR studies carried along Hajipur Fault (HF2) a branching out fault of Himalayan Frontal Thrust (HFT) in the foot hill zone of NW Himalaya (Figure 1). To identify the appropriate site for trenching and to understand the geometry of faulting, we collected 2D and 3D GPR profiles.

\section{Methodology}

Ground-penetrating Radar (GPR) is a noninvasive geophysical technique, where the high-frequency $(\mathrm{MHz})$ electromagnetic wave is transmitted into the ground that detects the electrical discontinuities in shallow subsurface earth material [12]. The propagation of the georadar waves is dependent on electrical properties of the material such as electric conductivity $(\sigma)$, magnetic permeability $(\mu)$, and dielectric permittivity $(\varepsilon)[12]$. When the georadar waves propagate down into the earth surface, they are refractedreflected back to the surface depending upon the properties of the lithology $[29,30]$. The unconsolidated sediments, construction material, and weathered or fractured rocks are porous in nature, hence if filled with water, affect dielectric permittivity or dielectric constant [30]. As the contrast in the subsurface layers is greater, the amount of reflected energy will be greater which is given by the reflection coefficient, $R$, and can be determined by the contrast in relative velocities and also by the contrast in relative dielectric constants [12]:

$$
R=\frac{V 1-V 2}{V 1+V 2} \quad \text { or } \quad \frac{\sqrt{\varepsilon 2}-\sqrt{\varepsilon 1}}{\sqrt{\varepsilon 2}+\sqrt{\varepsilon 1}},
$$

where, $V 1$ and $V 2$ are relative velocities, and $\varepsilon 1$ and $\varepsilon 2$ are relative dielectric constants of the adjacent layers. Velocity of 
the medium $(V)$ is dependent upon the velocity of light in air $(0.3 \mathrm{~m} / \mathrm{ns})$ and is given by a simplified equation:

$$
V=\frac{c}{\sqrt{\varepsilon}}
$$

where $c$ is velocity of light in air. Further, depth of penetration $(D)$ can be determined using two-way travel time $(T)$ and the velocity of the medium, which can be obtained from the graphical interpretation of the GPR signals:

$$
D=\frac{T * V}{2} .
$$

2.1. Data Acquisition along Hajipur Fault. GPR profiles were collected with SIR-3000 system using $200 \mathrm{MHz}$-shielded antenna in common-offset continuous mode. Variable settings available in the portable unit were used to determine the best acquisition parameters. For a better vertical resolution, the data was collected with 16-bit format and 512 Sample/scan whereas, $64 \mathrm{Scan} /$ unit (meter) was set for optimum horizontal resolution. Since the data was collected in a distance mode using survey wheel with 512 Sample/scan the rate of $100 \mathrm{Scan} / \mathrm{sec}$ was preferred. The floodplain deposits of Beas River is mainly comprised of sand + gravel deposits, with the top surface made up of medium-to-coarse sand with scattered gravels. Keeping in mind the usual dielectric constant of sand ranging from 3-6, higher value was attributed since the area was slightly moist. Finally, after having these parameters GPR profiles were collected, which gave a good resolution with penetration up to $6 \mathrm{~m}$ (Table 1 ). A calibrated odometer fixed on survey wheel was attached to the antenna to get the horizontal distance. Along with this, appropriate gain and IIR filter was applied to the field data to get better resolution and to remove noise with lower and higher frequencies, respectively.

At Sandhwal village, both 2D and 3D GPR profiling was carried out across the active fault scarp along Hajipur Fault (HF2), (Figure 2(a)). The 2D profile was $28 \mathrm{~m}$ long and was collected with the acquisition parameters given in Table 1 . Out of several profiles taken along this line, the profile shown in Figure 3 was the best one that exhibits ample information about the fault geometry. However, to have further understanding of the fault geometry, a $3 \mathrm{D}$ profile was collected for a grid-ABCD with dimensions of $20 \mathrm{~m} \times 6 \mathrm{~m}$ (Figures 2(b) and 4). For 3D profiling, the grid was prepared by taking $20 \mathrm{~m}$ along the $X$-axis and $6 \mathrm{~m}$ along the $Y$-axis and was further divided into smaller grids of $1 \mathrm{~m}$ spacing with which we have collected 21 grid lines along $X$-axis and 07 gridlines along $Y$-axis. The western corner (A) of the grid was considered as origin (Figure 2(b)). The data acquisition parameters for the 3D grid profile were the same as that of the $2 \mathrm{D}$ profile (Table 1 ). Since the surface across which the profile was collected was not horizontal, topographic profile was collected.

\section{Data Processing and Interpretation}

The radar profiles collected in the field were processed with RADAN 6.5 software manufactured by Geophysical Survey
TABLE 1: Acquisition parameters used for collection of 2D and 3D profiles across HF2 scarp at Sandhwal village.

\begin{tabular}{lc}
\hline Data acquisition parameters & Corresponding values \\
\hline Sample/scan & 512 \\
Bits/sample & 16 \\
Scan/sec & 100 \\
Scans/m & 64 \\
Dielectric constant & 6 \\
\hline
\end{tabular}

TABLe 2: Data processing parameters used for 2D and 3D GPR profiles across Hajipur Fault (HF2).

\begin{tabular}{cccc}
\hline \multicolumn{2}{c}{ Parameters } & 2D profile & 3D grid profile \\
\hline \multicolumn{2}{c}{ Time-zero correction } & $5.86 \mathrm{~ns}$ & $5.66 \mathrm{~ns}$ \\
\multirow{2}{*}{ FIR filters } & Low pass & $720 \mathrm{MHz}$ & $690 \mathrm{MHz}$ \\
& High pass & $38 \mathrm{MHz}$ & $40 \mathrm{MHz}$ \\
\multirow{2}{*}{ 3D grid } & $x$-(start-end) & - & $0 \mathrm{~m}-20 \mathrm{~m}$ \\
& $y$-(start-end) & - & $0 \mathrm{~m}-6 \mathrm{~m}$ \\
\hline
\end{tabular}

Systems, Inc. The 2D profile was processed in the sequence starting from time-zero correction, application of filters, surface normalization, and autogain restoration. The processing parameters for the $2 \mathrm{D}$ profiles and $3 \mathrm{D}$ grid are given in Table 2. The time-zero correction was applied to remove the uppermost high amplitude reflections obtained from the direct air wave and ground wave (Figure 3(a)) and for the successful realignment of all reflections beneath. The low- and high-pass filters along with background removal were applied to remove noise (interference). Topographic data collected along the same transect was incorporated in the $2 \mathrm{D}$ profile, and surface normalization was performed (Figure 3(a)). Automatic gain control (AGC) was applied to enhance the visibility of low-frequency features. The processing of the $3 \mathrm{D}$ grid profile was also done following the same steps as for the 2D GPR profiles. To have better view of the variation in fault geometry along the strike, the $3 \mathrm{D}$ profiles were vertically sliced.

3.1. Interpretation. Previous studies suggest that for the interpretation of GPR data and for locating near subsurface displacements in young Quaternary deposits, it is necessary to look for the offset of radar reflections on both sides of the fault strand and for the warping of the GPR reflectors or discontinuity in the reflections (e.g., $[10,11,30,31]$ ). Keeping the above points into consideration and with the background of the earlier paleoseismic and GPR surveys carried out along the Himalayan Frontal Thrust by Malik et al. [20, 23], attempts were made to interpret the GPR profiles taken for this study.

The 2D profile revealed prominent reflections in the form of hyperbolas between $4 \mathrm{~m}$ and $5 \mathrm{~m}$ horizontal markers and inclined discontinuities georadar reflections between $10 \mathrm{~m}$ and $28 \mathrm{~m}$ (Figure 3(a)). The hyperbolic reflections extending up to the depth of $2.5 \mathrm{~m}$ are interpreted as a metal pipe. In field, the local villagers informed that this was a main 


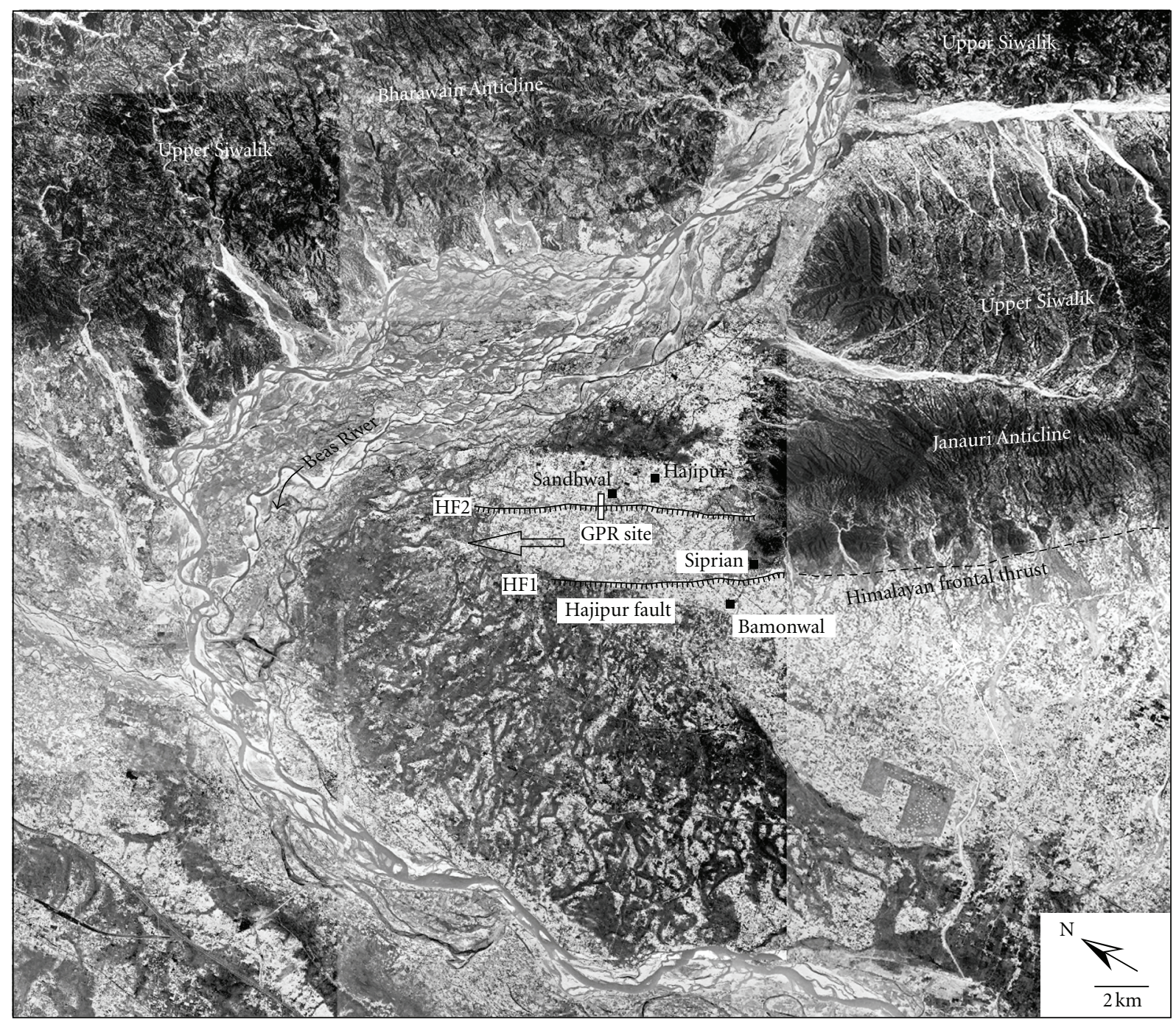

(a)

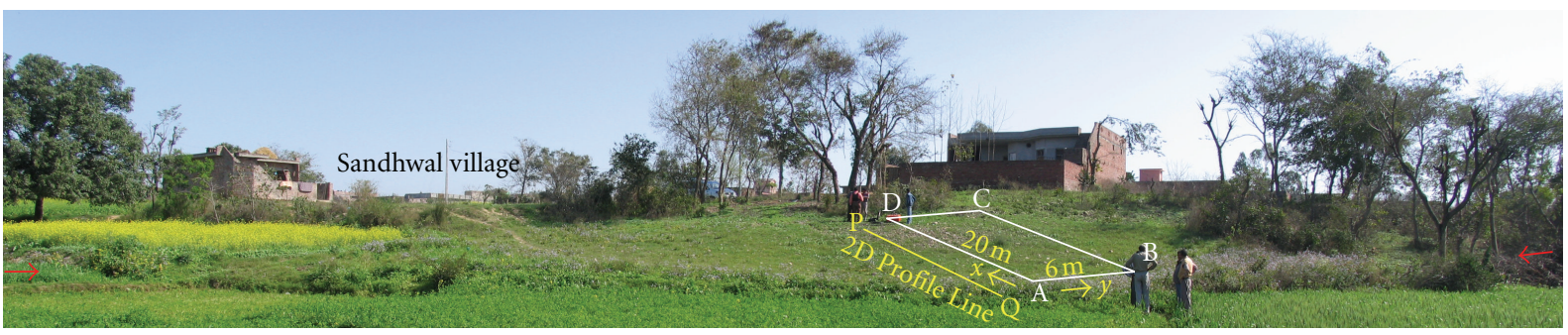

(b)

FIGURE 2: (a) CORONA satellite photo showing distribution of active fault traces named as "Hajipur faults"- HF1 and HF2 on the left bank of Beas River near Hajipur village [25]. Box shows the location of trench and GPR profile line across the HF2 fault scarp at Sandhwal village. Empty arrow marks the direction of fault propagation towards NW. Young tectonic movements along HF1 and HF2 faults resulted into uplift of floodplain deposits, responsible for the shifting/deflection of the Beas River channel along it present course. (b) Panoramic view of HF2-Hajipur fault scarp. PQ indicates the 2D scan, and ABCD indicates the 3D grid collected, respectively across the fault which is marked in red arrows.

pipeline that supplies water to a few surrounding villages. Looking the typical characteristic of the multiple inclined radar reflectors marked by discontinuous nature, with warping close to the dipping reflections, it is suggested that such a pattern was due to displacement of near subsurface young sediment succession caused by faulting (Figures 3(a) and $3(\mathrm{~b})$ ). The strong warping observed between $24 \mathrm{~m}$ and $28 \mathrm{~m}$ horizontal markers extending from $1 \mathrm{~m}$ to $5.5 \mathrm{~m}$ in 


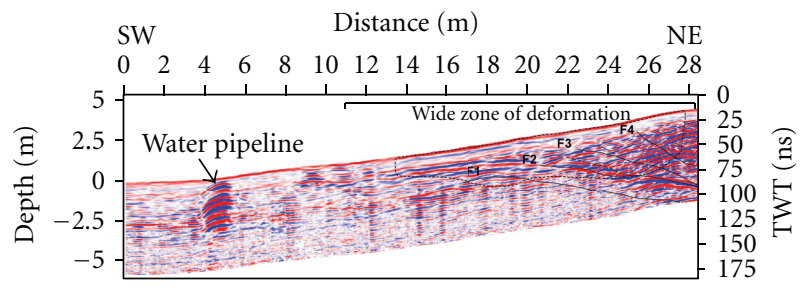

(a)

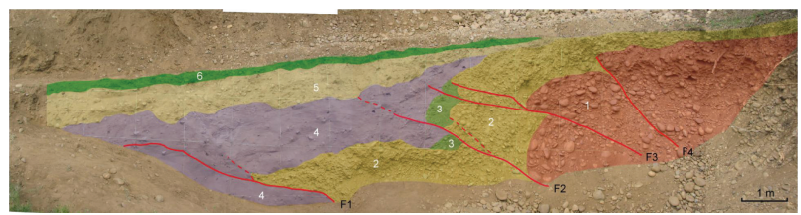

(b)

FIgURe 3: (a) Processed 2D GPR profile collected using $200 \mathrm{MHz}$ antenna across the HF2 scarp at Sandhwal Village (refer to Figures 2(a) and 2(b) for location). The profile was about $29 \mathrm{~m}$ long showing the processed profile after topographic correction. Reflections at 4-5 $\mathrm{m}$ indicate water pipeline, whereas the reflections from 14-28 m show the fault traces. Box with dotted line shows approximate area of a trench. (b) Interpretation with fault traces and stratigraphic units on north wall of trench excavated across HF2 fault scarp. F1, F2, F3, and F4 are the thrust faults dipping in NE direction. Latest event has been observed along F1, F2, and F3 displacing the units 1, 2, 3, and 4.

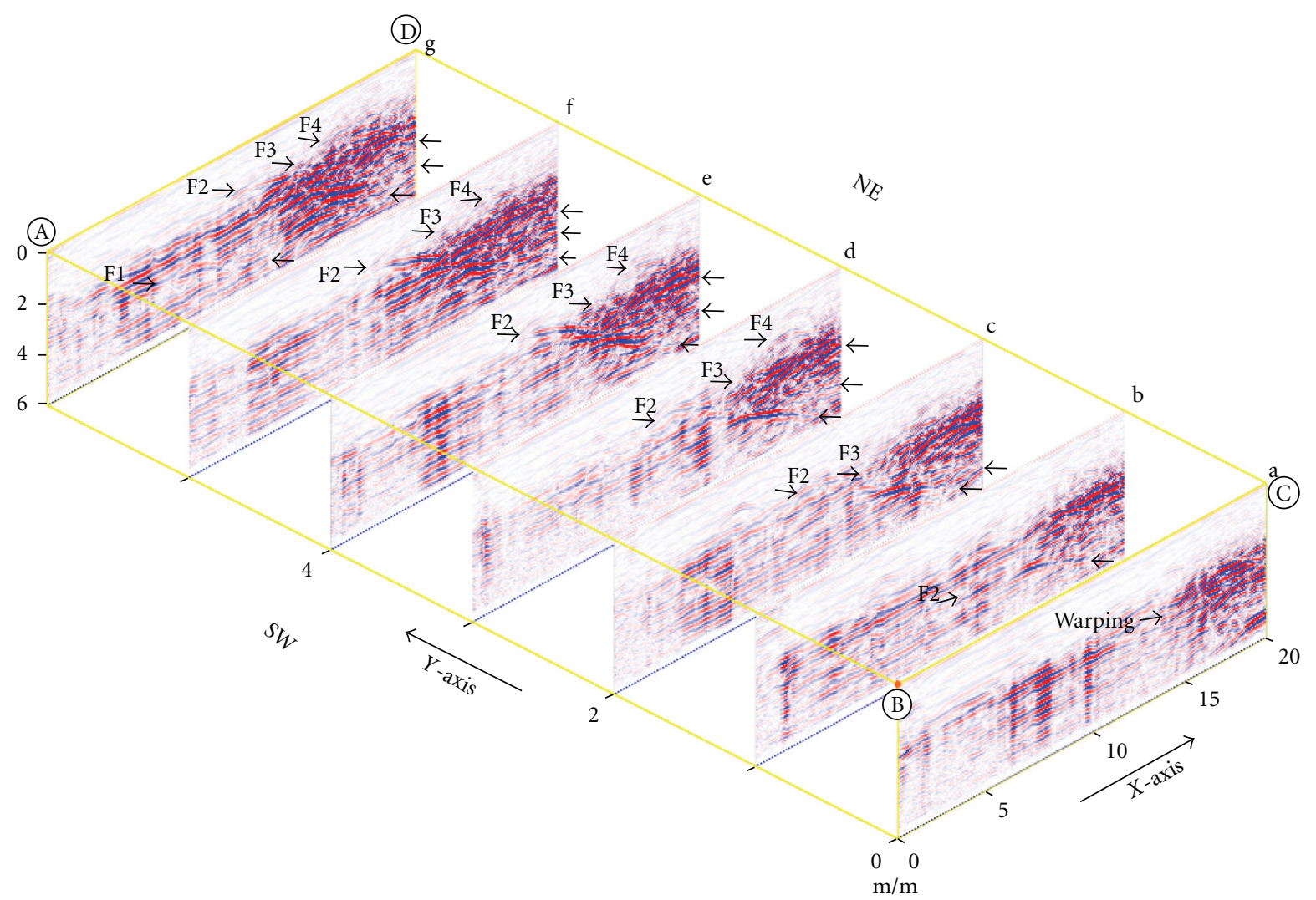

Figure 4: Sliced 3D grid profile across the HF2 scarp at Sandhwal Village collected with $200 \mathrm{MHz}$ antenna (refer to Figures 2(a) and 2(b) for location). The profile was collected for a grid-ABCD with dimensions of $20 \mathrm{~m} \times 6 \mathrm{~m}$. The dashed lines and arrowheads represent the faults. The grid was sliced along the $Y$-axis along the strike of the scarp at $1 \mathrm{~m}$ interval (seven slices from $a-g$ ). Changes in the pattern of deformation along the strike can be noticed from the slices. For location of the grid, refer to Figure 2.

depth is related to the deformation on hanging wall side (Figures 3(a) and 3(b)). Considering the angle of dip in the $2 \mathrm{D}$ profile, it can be suggested that the deformation is due to movement from NE to SW along a major low-angle thrust fault (Figures 3(a) and 3(b)). Discontinuity and warping of the reflectors along more than one inclined reflection suggest splays of branching faults from the main fault.

To have proper understanding of the fault geometry along the strike, 3D profile collected was vertically sliced at an interval of $1 \mathrm{~m}$ (Figure 4). The grid was sliced along the $Y$ axis (i.e., along the strike of the fault scarp) into seven layers with $1 \mathrm{~m}$ spacing, namely $a, b, c, d, e, f$, and $g$ (Figure 4 ). Each layer represents the line scan profile at $1 \mathrm{~m}$ interval. After close analysis, four low-angle fault strands were identified in slices $(a-g)$ which were named as F1, F2, F3, and F4. The F2 strand was identified in all slices, where in slices $a, b$, and $c$, it is marked by low-angle dipping towards NE between $10 \mathrm{~m}$ and $20 \mathrm{~m}$ horizontal markers and clearly traceable from 
surface up to $6 \mathrm{~m}$ of depth (Figure 4). Prominent warping of georadar reflections was observed on the northeast side of the fault plane, which represents the hanging wall. A change in dip of F2 strand was observed in slice $b$ (Figure 4). In addition to this other fault, strands F3 and F4 were seen in slices $d-g$. These strands are also dipping in NE direction with slightly higher angle. Strand F1 was observed between $3 \mathrm{~m}$ and $10 \mathrm{~m}$ horizontal markers in slice $g$ only. It is marked by slightly steeper angle in basal part and becomes almost subhorizontal towards the surface (Figure 4).

Based on the multiple fault strands identified in 2D and $3 \mathrm{D}$ profiles, it is suggested that the $\mathrm{F} 1$ is probably the main fault propagating towards foreland and F2, F3, and F4 are the branching out faults. The 3D slice $g$ and 2D profile collected gave similar features; hence, with this information for detailed paleoseismic investigation a trench with dimension- $16 \mathrm{~m}$ long, $4-5 \mathrm{~m}$ wide $1-3 \mathrm{~m}$ deep was excavated across the HF2 fault scarp in NE-SW direction [20] (Figure 3(b)). The trench wall matched the fault strands identified in GPR profiles (Figures 3(a) and 3(b)).

The splays, namely, F1, F2, F3, and F4 identified in GPR profiles were comparable with the exposed trench section (Figures 3(a) and 3(b)). Trench section revealed five sedimentary units 1-6. Units 1 and 2 are rounded to subrounded gravel-poorly sorted cobble-pebble with sandy matrix. These units are marked by high-prominent geo-radar reflections observed on the NE part of the profiles. The warping reflection can well be justified by the preferred orientation of gravel clasts, suggestive of folding related to faulting along the F1-F4 faults. The southern part of the trench is comprised of finer deposits as compare to the northern. These deposits are comprised of medium-to-fine sand (units 3-4). Unit 5 is made up of medium-to-coarse sand with scattered gravel finally caps the sequence. It is suggested that F1, F2, F3, and F4 are the thrust faults dipping in NE direction, and the latest event occurred along F1, F2, and F3 displacing the units $1,2,3$, and 4 . Because of the instability of trench wall due to coarser gravel clasts, we were not able to excavate the trench to see deeper section. However, the GPR profiles (2D and 3D) helped us tracing the fault at greater depth.

\section{Conclusion}

The GPR survey, 2D and 3D helped us in identifying the suitable location for trenching. The 3D profiling with slicing at $1 \mathrm{~m}$ interval gave a complete picture of variation in deformation in terms of the geometry of the fault and related deformation along the strike of the active fault (HF2). The $2 \mathrm{D}$ profile and slice $g$ of $3 \mathrm{D}$ profile were considered to open a trench for paleoseismic investigations. The prominent georadar reflections marked with discontinuities on either side of the inclined planes, warping suggested faulting along thrust faults. Also with the limitation to excavate trench up to greater depth, GPR profiles provide information on deformation and structure of greater depth. It is, therefore, suggested that GPR is one of the important tools which can be used for mapping the near subsurface displacements and variation in deformation along the strike of the active fault.

\section{Acknowledgments}

Financial support provided to the research project sponsored by DST, New Delhi, (vide project no. SR/S4/ES-417/2009) is duly acknowledged. We are grateful to two anonymous referees for providing valuable suggestions and comments, this helped us in improving the paper and brought more clarity to our findings. We are also thankful to our institute IIT Kanpur for providing support to our students.

\section{References}

[1] V. P. Solonenko, "Paleoseismogeology," Izvestiya, Academy of Sciences, USSR, Physics of the Solid Earth, vol. 9, pp. 3-16, 1973.

[2] K. Sieh, "Pre-historic large earthquakes produced by slip on the San Andreas Fault at Pallett Creek," Journal of Geophysical Research, vol. 83, pp. 3907-3939, 1978.

[3] R. E. Wallace, "Active faults, Palaeoseismology, and earthquake hazards in the Western United States," in Earthquake Prediction. An International Review, D. W. Simpson and P. G. Richards, Eds., pp. 209-216, American Geophysical Union, Washington, DC, USA, 1981.

[4] R. E. Wallace, "Variations in slip rates, migration, and grouping of slip events on faults in the Great Basin Province," Bulletin of Seismological Society of America, vol. 77, pp. 868876, 1987.

[5] D. P. Schwartz and K. J. Coppersmith, "Fault behavior and characteristic earthquakes: examples from the Wasatch and San Andreas fault zones (USA)," Journal of Geophysical Research, vol. 89, no. 7, pp. 5681-5698, 1984.

[6] C. R. Allen, "Seismological and paleoseismological techniques of research in active tectonics," in Active Tectonics, R. E. Wallace, Ed., pp. 148-154, National Academy Press, Washington, DC, USA, 1986.

[7] J. P. Mc Calpin, Ed., Paleoseismology, Academic Press, San Diego, Calif, USA, 1996.

[8] R. S. Yeats, K. Sieh, and C. R. Allen, Geology of Earthquakes, Oxford University Press, 1997.

[9] R. S. Yeats and V. C. Thakur, "Reassessment of earthquake hazard based on a fault-bend fold model of the Himalayan plate-boundary fault," Current Science, vol. 74, no. 3, pp. 230233, 1998.

[10] K. B. Anderson, J. A. Spotila, and J. A. Hole, "Application of geomorphic analysis and ground-penetrating radar to characterization of paleoseismic sites in dynamic alluvial environments: an example from southern California," Tectonophysics, vol. 368, no. 1-4, pp. 25-32, 2003.

[11] J. N. Malik and C. Mohanty, "Active tectonic influence on the evolution of drainage and landscape: geomorphic signatures from frontal and hinterland areas along the Northwestern Himalaya, India," Journal of Asian Earth Sciences, vol. 29, no. 5-6, pp. 604-618, 2007.

[12] A. Neal, "Ground-penetrating radar and its use in sedimentology: principles, problems and progress," Earth-Science Reviews, vol. 66, no. 3-4, pp. 261-330, 2004.

[13] J. P. Busby and J. W. Merritt, "Quaternary deformation mapping with ground penetrating radar," Journal of Applied Geophysics, vol. 41, no. 1, pp. 75-91, 1999.

[14] L. Liu and Y. Li, "Identification of liquefaction and deformation features using ground penetrating radar in the New Madrid seismic zone, USA," Journal of Applied Geophysics, vol. 47, no. 3-4, pp. 199-215, 2001. 
[15] J. C. Audru, M. Bano, J. Begg, K. Berryman, S. Henryys, and B. Niviere, "GPR investigations on active faults in urban areas: the Georisc-NZ project in Wellington, New Zealand," Comptes Rendus de l'Académie des Sciences-Series IIA- Earth and Planetary Science, vol. 333, no. 8, pp. 447-454, 2001.

[16] R. Gross, A. Green, K. Holliger, H. Horstmeyer, and J. Baldwin, "Shallow geometry and displacements on the San Andreas fault near Point Arena based on trenching and 3-D georadar surveying," Geophysical Research Letters, vol. 29, no. 20, pp. 34-1, 2002.

[17] A. Green, R. Gross, K. Holliger, H. Horstmeyer, and J. Baldwin, "Results of 3-D georadar surveying and trenching the San Andreas fault near its northern landward limit," Tectonophysics, vol. 368, no. 1-4, pp. 7-23, 2003.

[18] L. Slater and T. M. Niemi, "Ground-penetrating radar investigation of active faults along the Dead Sea Transform and implications for seismic hazards within the city of Aqaba, Jordan," Tectonophysics, vol. 368, no. 1-4, pp. 33-50, 2003.

[19] P. J. Alasset and M. Meghraoui, "Active faulting in the western Pyrénées (France): paleoseismic evidence for late Holocene ruptures," Tectonophysics, vol. 409, no. 1-4, pp. 39-54, 2005.

[20] J. N. Malik, A. A. Shah, A. K. Sahoo et al., "Active fault, fault growth and segment linkage along the Janauri anticline (frontal foreland fold), NW Himalaya, India," Tectonophysics, vol. 483, no. 3-4, pp. 327-343, 2010.

[21] B. K. Sternberg and J. W. McGill, "Archaeology studies in southern Arizona using ground penetrating radar," Journal of Applied Geophysics, vol. 33, no. 1-3, pp. 209-225, 1995.

[22] B. M. Whiting, D. P. McFarland, and S. Hackenberger, "Threedimensional GPR study of a prehistoric site in Barbados, West Indies," Journal of Applied Geophysics, vol. 47, no. 3-4, pp. 217226, 2001.

[23] J. N. Malik, A. K. Sahoo, and A. A. Shah, "Ground-penetrating radar investigation along Pinjore Garden Fault: implication toward identification of shallow subsurface deformation along active fault, NW Himalaya," Current Science, vol. 93, no. 10, pp. 1422-1427, 2007.

[24] S. Satuluri, "Ground penetrating radar application in archaeological investigations at ahichhatra, bareilly (Distt)," M.Tech Dissertation Report, Department of Civil Engineering, Indian Institute of Technology, Kanpur, India, 2009.

[25] J. N. Malik, A. K. Sahoo, A. A. Shah, D. P. Shinde, N. Juyal, and A. K. Singhvi, "Paleoseismic evidence from trench investigation along Hajipur fault, Himalayan Frontal Thrust, NW Himalaya: implications of the faulting pattern on landscape evolution and seismic hazard," Journal of Structural Geology, vol. 32, no. 3, pp. 350-361, 2010.

[26] L. Seeber and J. G. Armbruster, "Great detachment earthquakes along the Himalayan arc and long-term forecasting," in Earthquake Prediction. An International Review, D. W. Simpson and P. G. Richards, Eds., vol. 4 of Maurice Ewing Series, pp. 259-279, AGU, 1981.

[27] N. Ambraseys and R. Bilham, "A note on the Kangra $\mathrm{M}_{s}=7.8$ earthquake of 4 April 1905," Current Science, vol. 79, no. 1, pp. 45-50, 2000.

[28] N. N. Ambraseys and J. Douglas, "Magnitude calibration of north Indian earthquakes," Geophysical Journal International, vol. 159, no. 1, pp. 165-206, 2004.

[29] C. S. Bristow and H. M. Jol, Ground Penetrating Radar in Sediments, NO. 211, Geological Society, London, UK, 2003.

[30] Jol H. M., Ground Penetrating Radar: Theory and Applications, Elsevier Scientific, Oxford, UK, 2009.
[31] J. Chow, J. Angelier, J. J. Hua, J. C. Lee, and R. Sun, "Paleoseismic event and active faulting: from ground penetrating radar and high-resolution seismic reflection profiles across the Chihshang Fault, eastern Taiwan," Tectonophysics, vol. 333, no. 1-2, pp. 241-259, 2001. 

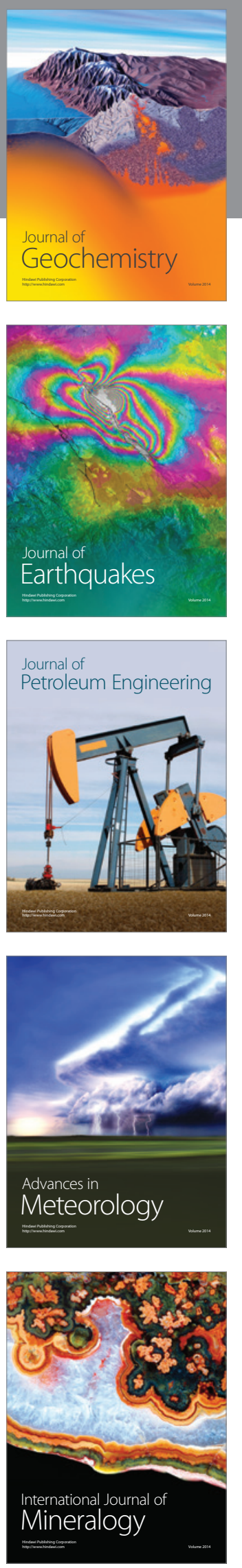
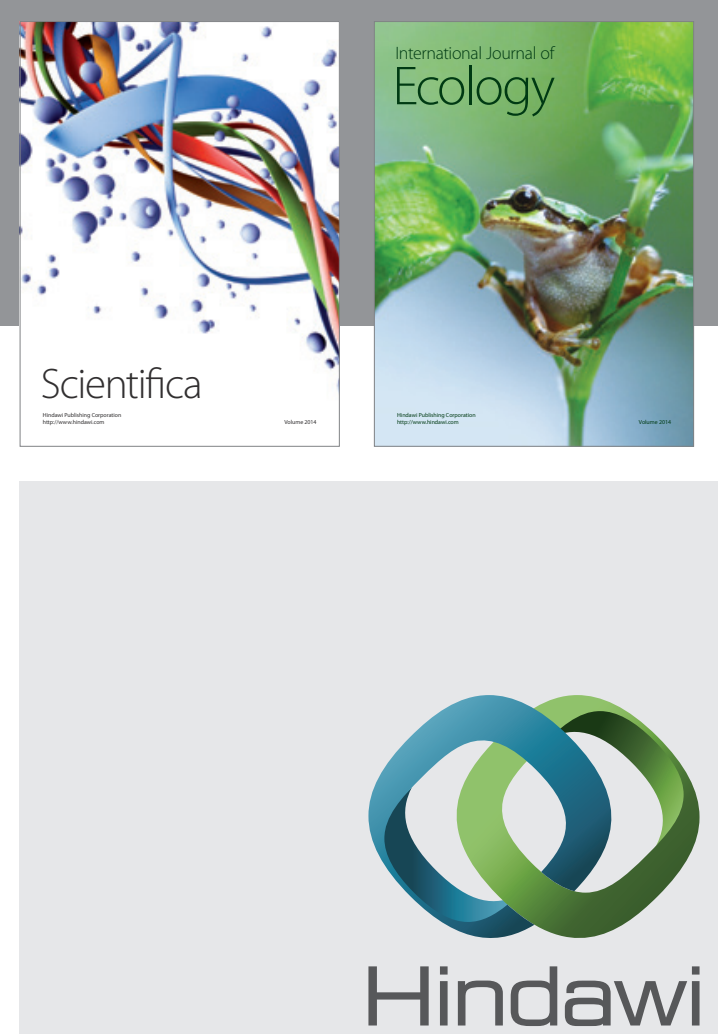

Submit your manuscripts at http://www.hindawi.com
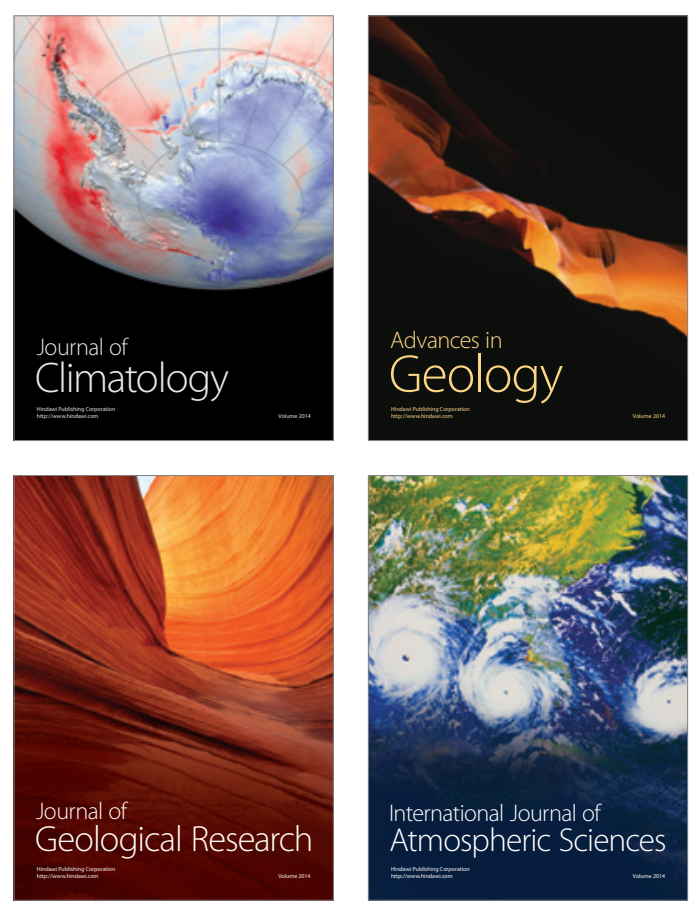
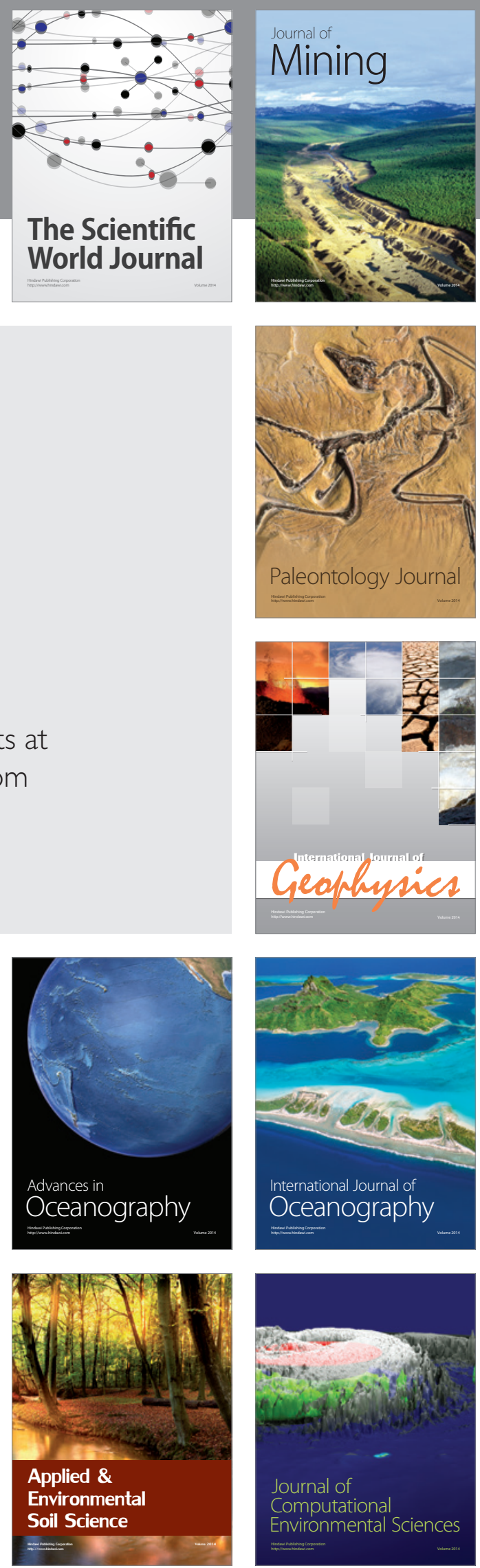